\section{An Index for Evaluating Fairy Ring Symptoms in Turfgrass}

\author{
Michael Fidanza ${ }^{1}$ \\ Division of Science, Berks Campus, Pennsylvania State University, Reading, \\ PA 19610
}

\author{
Derek Settle \\ Bayer Green Solutions Team, Bayer Environmental Science, Research \\ Triangle Park, NC 27709
}

\section{Henry Wetzel \\ Department of Crop and Soil Sciences, Washington State University, Pullman, WA 99164}

Additional index words. basidiomycete, hydrophobicity, soil, turf

\begin{abstract}
The term "fairy ring" typically refers to the visual appearance of mushrooms emerged in a circular pattern in a grass lawn, pasture, or meadow. Fairy ring symptoms in turfgrass stands are categorized as Type I (wilted, necrotic turf), Type II (dark green, stimulated turf), and Type III (basidiocarps present). A visual rating system was devised to assist researchers and practitioners with a numerical method to quantify the degree of severity of fairy ring symptoms at a turf site. Therefore, the Fairy Ring Severity Index is based on a 1 to 9 scale, where 1 indicates no fairy ring symptoms present, 2 through 5 indicates the low to high range for Type II symptoms, and 6 through 9 indicates the low to high range for Type I symptoms. For Type III symptoms, the number of mushrooms, toadstools, or puffballs present could be counted if that information is needed or helpful. In experimental research plots, the Fairy Ring Severity Index is a better method for evaluating and comparing fairy ring symptoms vs. using a percent plot area affected estimate.
\end{abstract}

Fairy ring is considered one of the most common turfgrass diseases globally, and over 60 species of basidiomycetes are known to cause fairy ring symptoms in turf, making it one of the most common turfgrass diseases globally (Couch, 1995; Smiley et al., 2005; Smith et al., 1989). Fairy ring symptoms observed in a turfgrass stand are the result of a complex interaction between the basidiomycete-causing fungus and the soil root zone and turfgrass thatch (Fidanza, 2015, 2007b; Fidanza et al., 2007). The medieval period is filled with folklore and strange tales of mushrooms magically appearing overnight in a circle (i.e., "fairy ring" since the cause was attributed to mythical fairies or "faeries") in pastures and woodlands (Wiggen and Smith, 2000), but the first scientific investigation into the soil chemistry of fairy ring-affected sites was published in 1807 (Wollaston, 1807). In 1917, Shantz and Piemeisel published their results of observing fairy ring sites in the grasslands of eastern Colorado, and developed a system to visually describe fairy ring

Received for publication 5 May 2016. Accepted for publication 28 July 2016.

We express our appreciation to many of the turfgrass industry professionals that shared photos of fairy ring-affected turfgrass sites on the Twitter social media identifier of \#FriskyFairyRingFriday. ${ }^{1}$ Corresponding author. E-mail: maf100@psu.edu. This is an open access article distributed under the CC BY-NC-ND license (http://creativecommons. org/licenses/by-nc-nd/4.0/). symptoms in nature labeled as Type I, Type II, and Type III. This same fairy ring scale

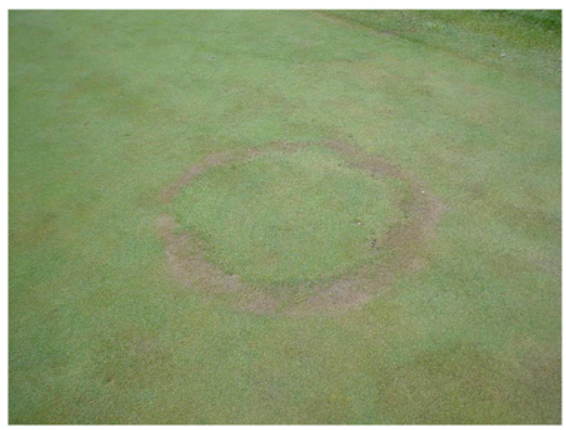

Fig. 1. Example of Type I fairy ring symptoms (necrotic, dead turf in a circle or ring) expressed in a cool-season turfgrass putting green.

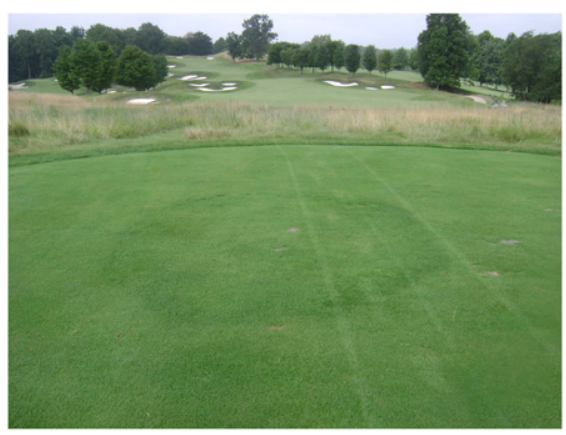

Fig. 2. Example of Type II fairy ring (dark green, stimulated, and lush-growing turfgrass in a circle or ring) in a cool-season turfgrass tee area. or categorical description was reintroduced and reemphasized in recent publications (Couch, 1995; Fidanza, 2009, 2015; Smith et al., 1989).

Type I fairy ring symptoms are characterized by dead turfgrass appearing in a peculiar geometric pattern of rings or semicircles or arcs (Fig. 1), as the result of a complex interaction of the basidiomycete fungus and the soil root zone and thatch (Couch, 1995; Fidanza, 2007a, 2007b; Fidanza et al., 2007; Shantz and Piemeisel, 1917; Smith et al., 1989). Type II symptoms are indicated by the visual appearance of darker green, stimulated, and lush-growing turf, also in a pattern of rings or semicircles or arcs, compared with the surrounding healthy turf (Fig. 2). Turf affected with Type II symptoms reveal a growth response similar to a dose of soluble nitrogen fertilizer (Fidanza, 2009; Fidanza et al., 2007; Smiley et al., 2005). Type II visual symptoms typically would be considered more visually acceptable compared with Type I symptoms (Fidanza, 2015). Type III symptoms (Fig. 3) are the visual appearance of basidiocarps (i.e., mushrooms or "toadstools" or "puffballs"), which represent the fruiting body or spore producing stage of the fungus (Shantz and Piemeisel, 1917). The mushrooms are often seen literally "popping-up" overnight after a heavy rain event. In turf, these visual fairy ring symptoms or "types" can occur alone (Figs. 1-3) or together (Fig. 4) in various combinations.

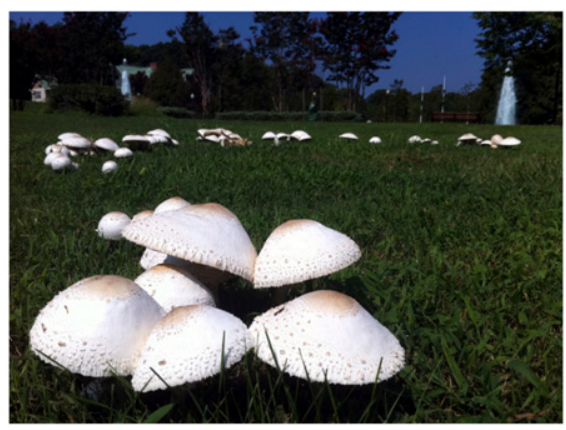

Fig. 3. Example of Type III fairy ring symptoms: mushrooms emerging in a lawn (photo courtesy of Jill Calabro).

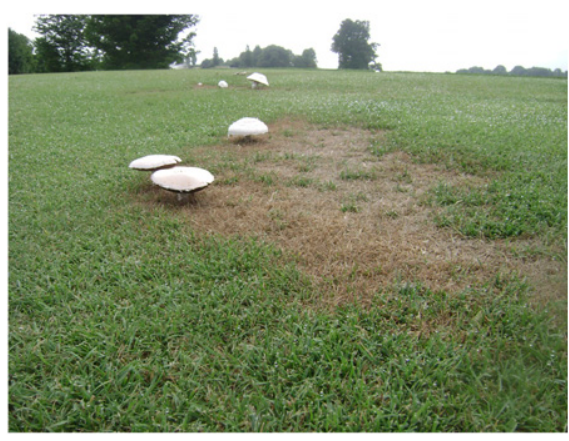

Fig. 4. Example of Type I (necrotic, dead turfgrass) and Type III (mushrooms) fairy ring symptoms observed together in a cool-season turfgrass fairway.

HortScience Vol. 51(9) September 2016 
In research, typical turfgrass disease rating strategies do not work as well for fairy ring (Fidanza and Settle, 2013; Fidanza et al., 2003, 2005). For example, dollar spot (Sclerotinia homoeocarpa F.T. Bennett) in turf is often rated by visually counting the number of active infection centers or foci per plot, which may work fine for counting individual mushrooms or puffballs, but not an area of wilted, necrotic, or dead turf within a test plot. Rhizoctonia blight or brown patch (Rhizoctonia solani Kühns) in turf usually is evaluated in test plots by estimating the percent plot area blighted. With fairy ring, a percent plot area blight rating may not reveal the correct interpretation of fairy ring activity or turfgrass injury (Fig. 5). For example, at first glance it may seem that a $5 \times 5 \mathrm{ft}(1.5 \times 1.5 \mathrm{~m})$ test plot with $50 \%$ plot area affected by dark green, stimulated turf in an arc or small circle (i.e., Type II fairy ring symptoms) would be more severe compared with another test plot that had $10 \%$ plot area affected with necrotic and dead turf in a small semicircle (i.e., Type I). In reality and in terms of judging the complex threat of fairy ring symptoms in turf, a $10 \%$ plot area of necrotic or dead turf would be considered much more severe and troublesome and difficult to manage vs. 50\% plot area of dark green, stimulated turf (Fidanza, 2009; Fidanza and Settle, 2013). Of course, the

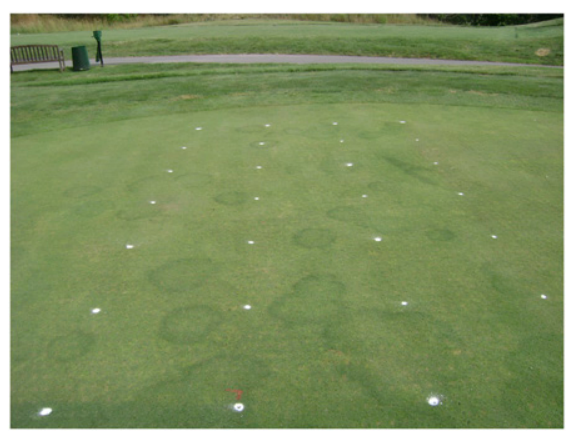

Fig. 5. Example of experimental research plots, as indicated by white dots painted at plot corners, placed over Type II fairy ring symptoms in a coolseason turfgrass practice chipping green. diameter of actual fairy ring symptoms in turf can vary from a few inches $(\mathrm{cm})$ to several feet (m) (Smith et al., 1989). Also, it is extremely difficult to visually estimate the actual percent plot area displaying fairy ring symptoms. For example, does one measure the entire circular area of a fairy ring, or, measure only the specific dark green perimeter area of the circle (Fig. 5)? Therefore, over the past several years with conducting fairy ring trials and field studies in turf, it has become evident that a better rating system was needed. The goal of this project was to develop a "Fairy Ring Severity Index" to help quantify and categorize visual fairy ring symptoms in turf.

\section{Fairy Ring Severity Index}

This index uses a 1 to 9 scale to sequentially quantify the combined appearance in severity and turfgrass injury of Types I and II fairy ring symptoms expressed in a turfgrass stand (Table 1; Fig. 6A-F). Often, Types I and II fairy ring symptoms occur together at the same specific site. For example, Type II symptoms of dark green turfgrass in rings or semicircles can appear first, followed a few or several days later with wilted turf along the inside or outside ring perimeter which progresses into severe Type I symptoms of necrotic, dead turf (Fidanza, 2015; Fidanza et al., 2007; Settle and Fidanza, 2007). The Fairy Ring Severity Index follows this progression from no visual symptoms present represented by the numerical value of 1 , Type II severity symptoms being represented by the 2 to 4 numerical scale, a transition of Type II to Type I symptoms represented by 5 and 6, and Type I severity symptoms represented by 7 to 9 (Table 1 ).

What if Type III symptoms (i.e., mushrooms) are currently present or appear later in conjunction with Type I and II symptoms (Fig. 4)? Along with this Fairy Ring Severity Index, the mushrooms or puffballs can simply be counted (i.e., number of basidiocarps per test plot) to gain a quantitative account if that is of interest to the investigator or if that data adds value to the research (Fig. 7) (Fidanza et al., 2003).

\section{Summary}

In conclusion, although visual determination of fairy ring symptoms in turf can be subjective, the Fairy Ring Severity Index can be an effective method to quantify the negative impact of fairy ring activity in turf, as well as measure turf recovery from biological, cultural, and/or chemical treatments (Fidanza and Settle, 2013; Fidanza et al., 2003). In a way, this Fairy Ring Severity Index is similar to the HorsfallBarratt scale commonly used in plant disease assessment, which is semiquantitative and helpful to compensate for human error in determining percentages (Campbell and Madden, 1990). Data from the Fairy Ring Severity Index can be statistically analyzed by subjecting the data to analysis of variance and treatments compared using various mean comparison tests (Mead et al., 2003). Percent disease severity data often requires transformation (i.e., arcsine or arcsine square root transformation) to correctly analyze the proportional data in a valid or statistically meaningful way (Campbell and Madden, 1990). Also, the "area under the fairy ring index curve" can be calculated to quantify fairy ring symptom expression over time. Future improvements to this Fairy Ring Severity Index could be possible by quantifying turf color, turf canopy reflectance, and turf necrosis using digital image analysis and spectral radiometry (Karcher and Richardson, 2003).

\section{Literature Cited}

Campbell, C.L. and L.V. Madden. 1990. Introduction to plant disease epidemiology. Wiley-Interscience, New York, NY.

Couch, H.B. 1995. Diseases of turfgrasses. 3rd ed. Krieger Publishing, Malabar, FL.

Fidanza, M. 2007a. New insight into fairy ring. Golf Course Mgt. 75(3):107-110.

Fidanza, M.A. 2007b. Characterization of soil properties associated with type-I fairy ring symptoms in turfgrass. Biologia 62(5):533536.

Fidanza, M. 2009. Fairy ring 101: The curious, elusive, but troublesome fairy ring. USGA Green Section Record 47(2):8-10.

Table 1. Description of the Fairy Ring Severity Index in turfgrass.

\begin{tabular}{|c|c|}
\hline & The Fairy Ring Severity Index is based on a visually determined 9-point scale as follows \\
\hline 1 = No symptoms & \\
\hline $\begin{array}{l}2=\text { Type II, slight } \\
3=\text { Type II, moderate } \\
4=\text { Type II, severe }\end{array}$ & $\begin{array}{l}\text { Darker green turf in affected areaz compared with surrounding area without symptoms, ranging from slight or "light green" } \\
\text { to severe or "dark green" similar to a dose of soluble nitrogen fertilizer, and possibly or most likely stimulated, } \\
\text { lush growing turf }\end{array}$ \\
\hline $\begin{array}{l}5 \text { = Type II, very severe } \\
\text { progressing into Type I }\end{array}$ & $\begin{array}{l}\text { Extreme, dark green turf, and most likely stimulated, lush growing turf, and wilting observed on the perimeter/leading } \\
\text { edge of symptom area indicating the progression or development into Type I symptoms }\end{array}$ \\
\hline
\end{tabular}

$8=$ Type I, severe

${ }^{2}$ Fairy ring symptoms in turf in patterns of rings or circles or arcs expressed as Type II symptoms indicated by dark green, stimulated turfgrass, and Type I symptoms indicated by wilted, necrotic, damaged, or dead turfgrass (Couch, 1995; Fidanza, 2009, 2015; Shantz and Piemeisel, 1917; Smith et al., 1989). 
A

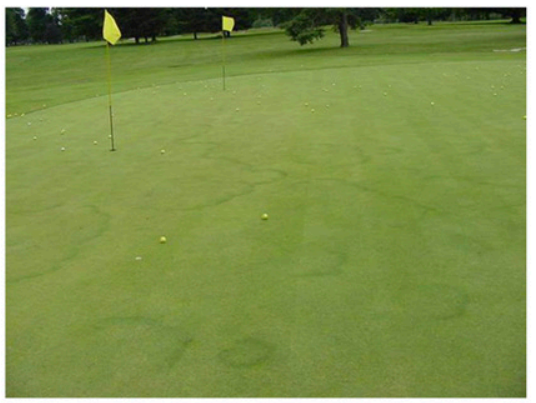

D

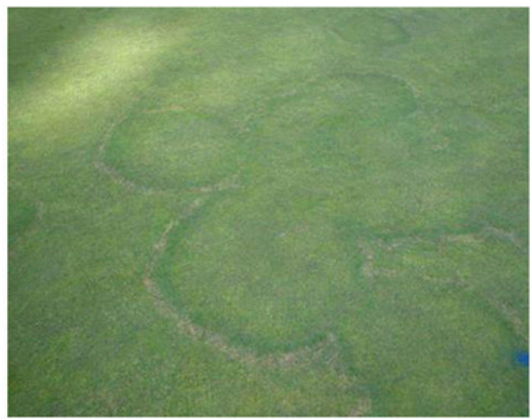

B

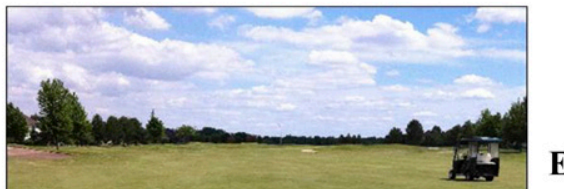

$\mathbf{E}$

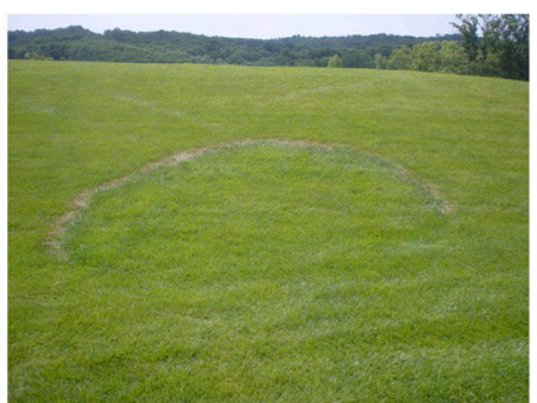

C

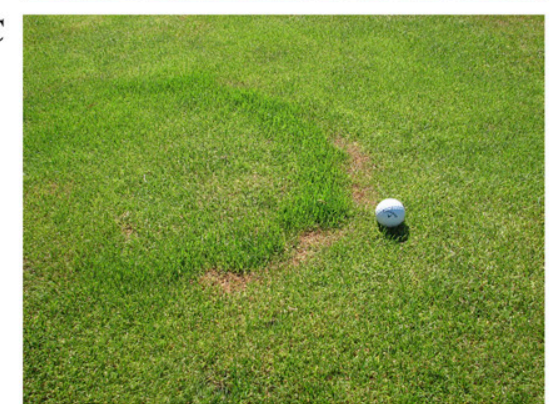

F

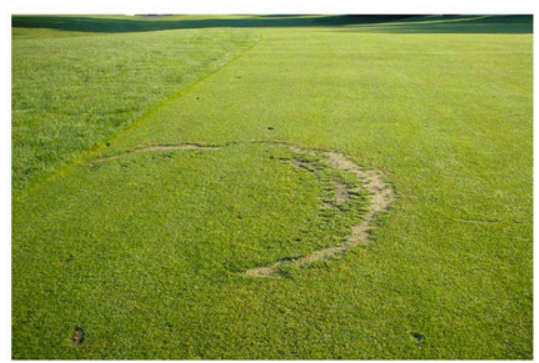

Fig. 6. (A) Example of a "2" on the Fairy Ring Severity Index, as indicated by darker green, slightly stimulated or actively growing turfgrass compared with the unaffected areas of this practice coolseason turfgrass putting green. (B) Example of a " 4 " on the Fairy Ring Severity Index, as indicated by very dark green, stimulated, lush-growing turfgrass compared with the unaffected areas of this coolseason turfgrass fairway. (C) Example of a " 5 " on the Fairy Ring Severity Index in a cool-season turfgrass fairway, as indicated by Type II symptoms appearing along the ring perimeter (i.e., stimulated and dark green turf compared with the nearby unaffected area), and developing into Type I symptoms along the outer edge (i.e., wilted, brown turf forming a necrotic zone). (Photo courtesy of Adam Moeller). (D) Example of a " 5 " and progressing to a "6" on the Fairy Ring Severity Index in a coolseason turfgrass fairway, as indicated by the outer edge of the stimulated, dark green Type II symptoms developing into wilted and necrotic Type I symptoms. (E) Example of a "7" and progressing to an " 8 " on the Fairy Ring Severity Index, as indicated by severe, wilted, necrotic, and "nearly" dead turf appearing in a semicircle pattern in a cool-season turfgrass golf course rough area. (F) Example of a "9" on the Fairy Ring Severity Index, as indicated by very severe, necrotic, and dead turf appearing in a semicircle pattern in a cool-season turfgrass golf course fairway area.

Fidanza, M. 2015. Understanding and controlling fairy ring. Pennsylvania Turfgrass 4(1):10-16.
Fidanza, M. and D. Settle. 2013. Evaluation of an inorganic soil amendment to reduce and

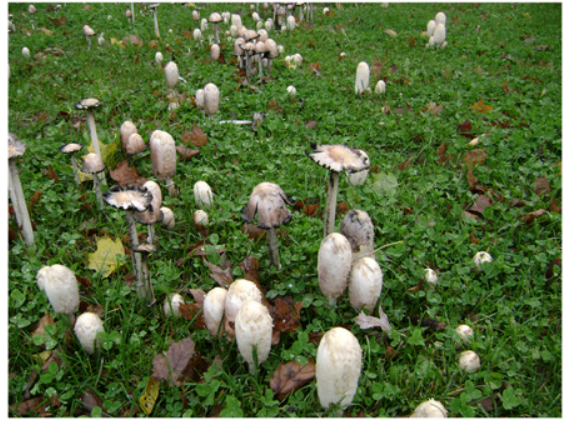

Fig. 7. Example of an excessive amount of Type III fairy ring symptoms [i.e., mushrooms of Coprinus comatus (O.F. Müll.) Pers.] appearing on this cool-season lawn area.

manage fairy ring symptoms in turfgrass. USGA Turfgrass Environmental Res. Online 12(3):6-8.

Fidanza, M.A., D.L. Sanford, H. Wetzel, Jr., and J.S. Nattle. 2003. Evaluation of fungicides, a soil wetting agent, and cultural practices for curative fairy ring control, 2001. Fungicide and Nematicide Tests 58:T036.

Fidanza, M.A., J.L. Cisar, S.J. Kostka, J.S. Gregos, M.J. Schlossberg, and M. Franklin. 2007. Preliminary investigation of soil chemical and physical properties associated with type-I fairy ring symptoms in turfgrass. Hydrol. Processes 21:2285-2290.

Fidanza, M.A., P.F. Colbaugh, M.C. Engelke, S.D. Davis, and K.E. Kenworthy. 2005. Use of highpressure injection to alleviate type-I fairy ring symptoms in turfgrass. HortTechnology $15: 169-172$.

Karcher, D.E. and M.D. Richardson. 2003. Quantifying turfgrass color using digital image analysis. Crop Sci. 43:943-951.

Mead, R., R.N. Curnow, and A.M. Hasted. 2003. Statistical methods in agriculture and experimental biology. 3rd ed. Chapman and Hall/ CRC, Boca Raton, FL.

Settle, D. and M. Fidanza. 2007. Fairy ring research. On Course. J. Midwest Assn. Golf Course Superintendents 61(3):11-15.

Shantz, H.L. and R.L. Piemeisel. 1917. Fungus fairy rings in eastern Colorado and their effects on vegetation. J. Agr. Res. 11:191-245.

Smiley, R.W., P.H. Dernoeden, and B.B. Clark. 2005. Compendium of turfgrass diseases. 3rd ed. APS Press, Minneapolis, MN.

Smith, J.D., N. Jackson, and A.R. Woolhouse. 1989. Fungal diseases of amenity turf grasses. E \& F.N. Spon Ltd, London, UK.

Wiggen, K.D. and N.A. Smith. 2000. The fairy ring: Favorite fairy tales of many countries. Reprinted from 1910 edition. Fredonia Books, Amsterdam, The Netherlands.

Wollaston, W.H. 1807. On fairy rings. Philos. Trans. R. Soc. Lond. 2:133-138. 